\title{
Species richness of soil and leaf litter tardigrades in the Great Smoky Mountains National Park (North Carolina/Tennessee, USA)
}

\author{
Diane R. NELSON, ${ }^{1 *}$ Paul J. BARTELS ${ }^{2}$ \\ ${ }^{1}$ Department of Biological Sciences, East Tennessee State University, Johnson City, TN 37614; ${ }^{2}$ Department of Biology, \\ Warren Wilson College, Asheville, NC 28815, USA \\ *Corresponding author: nelsond@etsu.edu
}

\begin{abstract}
A large database now exists for tardigrades in the Great Smoky Mountains National Park (GSMNP) consisting of 780 samples, 15,618 specimens, and 80 species including 14 new to science. We found 43 species of tardigrades in 150 soil/leaf litter samples. We calculated the Chao 1 species richness estimate with the species accumulation curve for the GSMNP and confirmed that our species list is virtually complete. Compared with soil data from mt. Fuji, Japan, estimated species richness in GSMNP was significantly higher. In our comparison of previous studies of soil/leaf litter tardigrades in other geographic areas, only the Kanagawa prefecture of Japan reported a higher number of species (47) than the GSMNP. Species richness estimators are valuable tools for comparing diversity in different habitats, even when sampling effort varies between studies.
\end{abstract}

Key words: soil ecology, leaf litter ecology, species diversity, species richness, community composition, biodiversity.

\section{INTRODUCTION}

Soil ecology is a rapidly growing field, driven by a new understanding that there may be more biological diversity in the soil than on it (Wall et al., 2005) and that these soil communities provide essential ecosystem services (Wall et al., 2007). Tardigrades are a consistent and ubiquitous component of soil food webs (Wu et al., 2009), yet they remain poorly studied in the soil/leaf litter habitat.

A number of publications have recorded tardigrades from soil and/or leaf litter. These tardigrade species were first thought to be accidental occurrences but later considered as permanent components of the soil ecosystem. Tardigrade diversity, abundance, and distribution in these habitats were investigated primarily in forests (Hallas and Yeates, 1972; Ito, 1999; Ito and Abe, 2001) and rarely in grasslands (Manicardi and Bertolani, 1987). Some studies also examined the effect of environmental factors on these tardigrade communities. For example, Guidetti et al. (1999) compared seasonal and altitudinal effects on depth distribution in forest leaf litter. Hinton et al. (2010) studied the diversity and density of tardigrades in the upper and lower horizons of leaf litter from Louisiana and Florida and compared their results with those of Guidetti et al. (1999). In Antarctica, Petz (1997), Porazinska et al. (2002), Moorhead et al. (2003), Sohlenius et al. (2004), and Sohlenius and Boström (2008) correlated tardigrade abundance with other micrometazoans, soil types, and possible environmental factors.

Investigations on the effects of anthropogenic impacts on tardigrade depth distribution and abundance in soil and/or leaf litter were conducted by Fleeger and Hummon
(1975) (old-field cultivation), Leetham et al. (1980, 1982) ( $\mathrm{SO}_{2}$ exposure), Sohlenius (1982) (clear-cutting), Uhia and Briones (2002) (deforestation), and Hohberg (2006) and Hohberg et al. (2011) (mine reclamation and succession).

Most of these studies presented data graphically, but few attempts were made to analyse the data statistically. In contrast, Harada and Ito (2006) reported a multivariate statistical analysis of forest soil tardigrades and analysed environmental variables. In a large-scale, multihabitat study, Guil (2008) and Guil et al. (2009) used parametric and non-parametric statistics to analyse environmental variables and tardigrade species diversity and abundance.

Since 2000, we have been working on a large-scale, multihabitat inventory of the Great Smoky Mountains National Park (GSMNP), Tennessee and North Carolina, USA (Bartels and Nelson, 2006, 2007, 2012; Bartels et al., 2007, 2008, 2009, 2011a, 2011b; Nelson and Bartels, 2007). GSMNP is renowned as a center for temperate biodiversity, and it is designated as a Biosphere Reserve and a World Heritage Site. The park is $>20,000$ ha with 79 unique vegetation communities and over 1600 species of vascular plants including many endemic to the Southern Appalachian mountains (White et al., 2003). Composed of very complex topography (267-2025 m asl), geology, and soils (Jenkins, 2007), GSMNP has been subject to major anthropogenic impacts, including a history of forest clearing, a number of invasive exotics, and acid precipitation.

One of the habitats we have investigated in our GSMNP inventory is soil/leaf litter. In this paper, we have listed the species identified from this habitat, compared the Chao 1 species richness estimate with the species ac- 
cumulation curve, and compared species richness with other large scale soil and/or leaf litter studies. Species distribution modeling using MaxEnt software (Elith et al., 2011) will be presented in a subsequent paper.

\section{METHODS}

The tardigrade inventory in the Great Smoky Mountains National Park (GSMNP) is part of the much larger all taxa biodiversity inventory (ATBI) (www.dlia.org). The basic collecting, processing, and examination methods used to inventory tardigrades found in the park's many habitats (mosses and lichens on trees, stream sediments and periphyton, and soil/leaf litter) in the ATBI plots were described in Bartels and Nelson (2006). Briefly, terrestrial field samples were placed in paper bags and air-dried. They were rehydrated with tap water, processed in the lab with Ludox ${ }^{\mathrm{AM}}$ centrifugation, and preserved with $70 \%$ boiling ETOH. Specimens were individually mounted on slides in Hoyer's or Polyvinyl Alcohol (PVA). Coverslips were sealed with enamel paint. Because of the large number of samples for the entire multihabitat inventory, a maximum of 50 adults plus eggs were mounted per sample. Animals were identified using standard taxonomic analysis with an Olympus BX-60 microscope (Olympus, Center Valley, PA, USA) with phase contrast and DIC.

Soil/leaf litter samples were collected by scraping away the non-decomposed leaves and collecting down to a depth of about $2 \mathrm{~cm}$ in approximately a $10 \mathrm{~cm}^{2}$ area, including both the decomposing leaf litter and the surficial soil levels. These samples were sub-sampled during the centrifugation process. Twelve centrifuge tubes were used per sample, roughly standardizing the volume of substrate examined across samples. As measured by wet volume in the centrifuge tubes, this equaled approximately $25 \mathrm{cc}$ of soil/leaf litter processed per sample.

Two soil/leaf litter sample datasets were used for this study. The first consisted of the initial samples collected for the ATBI. These were collected at 19 permanent ATBI plots established for long-term monitoring of a variety of taxa. These plots were chosen to represent the major types of land cover in the park, some repeated at multiple elevations (Jenkins, 2007). At each of the ATBI plots we collected four replicates of soil/leaf litter samples systematically, not randomly. The samples were collected near the base of the trees from which we collected moss and lichens in order to include a variety of leaf litter types. When multiple soil types were present in one plot, we attempted to sample from the dominant soil type. We named this the basic dataset, which consisted of 76 total samples (19 plots X 4 replicates). Samples in this basic dataset were collected from May to November in 2001, 2002, 2003, 2005, and 2008. We added a second soil sample dataset that came from two unpublished student projects (Cosby Campground and Snakeden ridge), an additional sample from the base of a limestone sinkhole in the northwest area of the park, and three extra samples from several of the ATBI plots. We called this the supplemental dataset, which included an additional 74 samples collected April through October 2005, 2006, and 2008. For all samples, latitude and longitude were recorded with GPS. All collecting sites are illustrated in Fig. 1. We used EstimateS 8.2 (Colwell, 2009) to calculate a species accumulation curve and a Chao1 species richness estimate for the complete set of GSMNP soil/leaf litter samples as well as for the soil data from $\mathrm{mt}$. Fuji, Japan (Ito, 1999) supplied by Dr. Ito. We then used a t-test to determine if the difference in species richness in GSMNP and mt. Fuji was significant.

\section{RESULTS}

\section{Soil/leaf litter tardigrades in the Great Smoky Mountains National Park}

The basic dataset included 76 samples (66 of which contained tardigrades), 1455 specimens identified to species, and 40 species. The supplemental dataset included 74 samples (48 of which contained tardigrades), 281 specimens identified to species, and 17 species, 3 of which were unique relative to the basic dataset. Thus, the entire soil data consisted of 150 samples (114 of which contained tardigrades, 76\%), 1736 individuals identified to species, and 43 total species. The species list is given in Tab. 1 .

A species accumulation curve and a Chaol species richness estimate were calculated for the complete set of soil samples (Fig. 2). The observed species $\left(\mathrm{S}_{\mathrm{obs}}\right)$ curve is nearing an asymptote at 43 species, and the final Chao1 species richness estimate of 45 is very close to the total species in our samples. Thus, we know our species list is virtually complete.

\section{Comparison with other studies}

We wanted to compare our GSMNP soil/leaf litter tardigrade diversity (43 species, 150 samples) with other geographic areas, however it was difficult to find comparable studies. Tab. 2 shows the number of tardigrade species reported from soil and/or leaf litter samples from other studies that focused on the same habitats either solely or as part of a multihabitat study. The number of samples varied widely, as did the scale of the studies, the techniques employed, and the substrates analysed. For example, the Costa Rican soil samples analysed by Kaczmarek (2003) were actually mosses growing on soil, and in Guil (2008) the leaf litter samples did not include soil. The study in the Kanagawa prefecture of Japan (Harada and Ito, 2006) is the only study with higher species richness than GSMNP.

Chao 1 species richness estimates are comparable between sites even with differing sampling effort. Although raw data for the Kanagawa study (Harada and Ito, 2006) were not available for analysis, Ito sent us the mt. Fuji data 
(Ito, 1999) from surface soil and leaf litter (as in our GSMNP study). Our sampling differed in that Ito sampled approximately $100 \mathrm{cc}$ of soil per sample while we sampled about $25 \mathrm{cc}$, and he sampled to $5 \mathrm{~cm}$ soil depth while we sampled only to about $2 \mathrm{~cm}$. Fig. 3 compares Chao 1 species richness estimates for our GSMNP data and Ito's mt. Fuji data. A t-test on the asymptotic (maximum) values of the Chao 1 species richness estimates showed a significant difference between GSMNP and mt. Fuji $(\mathrm{t}=11.52$, $\mathrm{P}<0.0001)$.

\section{DISCUSSION}

\section{Previous distribution and abundance studies}

Hallas and Yeates (1972) extracted 10 species of tardigrades from humus (litter) and soil in a Danish beech for- est (Fagus sylvatica L.) and compared the depth distribution of the species. They estimated abundance of each species in their monthly samples, noting seasonal variation in the species and very high variation in abundance between samples. Ito (1999) reported high variability in abundance, density, and habitat preference (soil, moss, lichen) of tardigrades in various forests on mt. Fuji, Japan. Ito and Abe (2001) graphed differences in the micro-distribution of the dominant soil tardigrades in $1 \mathrm{~cm}$ layers $(0-10 \mathrm{~cm})$ in the 18 species in a Japanese sub-alpine coniferous forest (Abies veitchii Lindl.).

Guidetti et al. (1999) compared the effects of season, elevation, and soil depth on leaf litter tardigrade distributions in beech forests of Roan mountain, Tennessee, USA, (Fagus grandifolia Ehrh.), and the Apennine mountains of Italy (F. sylvatica). In Tennessee, 26 species of eutardi-

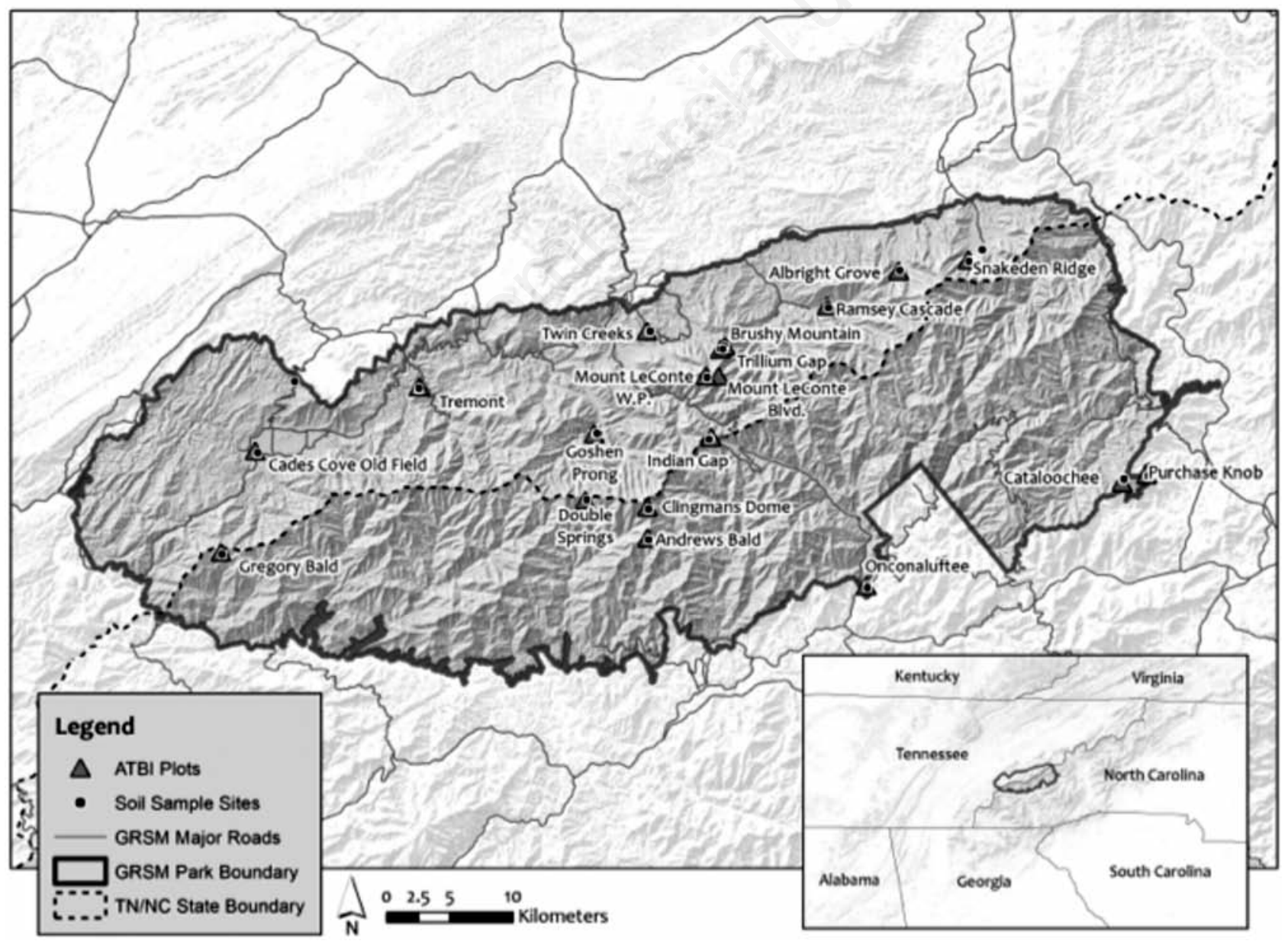

Fig. 1. Map of Great Smoky Mountains National Park showing soil sample collecting sites. Triangles indicate the 19 permanent all taxa biodiversity inventory plots. Circles without triangles mark the locations of the supplemental collections. 
grades and 6 species of heterotardigrades (very low abundance) were found. In Italy, 20 species of eutardigrades were found on Mount Rondinaio (14 sp.) and Piane di Mocogno (15 sp.). Of the total of 43 species in Tennessee and Italy, only 7 were present on both continents. Abundance and diversity were higher in the upper layers of the leaf litter. Some seasonal and altitudinal differences were depicted graphically.

Leaf litter samples from deciduous and pine forests in Louisiana and Florida (USA) contained fewer species and lower densities of tardigrades (Hinton et al., 2010) than Guidetti et al. (1999) found in beech forests in Tennessee (USA) and Italy. Only 6 species were present in two sites in Louisiana and 5 species in one site in Florida. Diversity and abundance (377 of 439 specimens) were both higher in the upper leaf litter layer.
In Antarctica, Petz (1997) investigated soils and mosses and found correlations between the abundance of tardigrades and other micrometazoans. Maximum densities of all groups were found in mosses. Micrometazoan populations in general increased with an increase in soil water content, air temperature, and soil organic matter (loss on ignition). Nematode and tardigrade densities sometimes decreased with an increase in $\mathrm{pH}$ or soil temperature, although the decreases were not statistically significant for tardigrades. Porazinska et al. (2002) and Moorhead et al. (2003) indicated that the patchy distribution of suitable Antarctic soil habitats for micrometazoans (nematodes, tardigrades, and rotifers) and a combination of soil factors (soil moisture, organic carbon, and salinity) may limit micrometazoan abundance and diversity. In addition, Sohlenius et al. (2004) and Sohlenius and Boström

Tab. 1. Alphabetical species list for soil samples from Great Smoky Mountains National Park.

\begin{tabular}{|c|c|c|c|}
\hline Species & N. of samples & Species & N. of samples \\
\hline Astatumen trinacriae (Arcidiacono, 1962$)^{*}$ & 46 & Isohypsibius basalovoi (Durante and Maucci, 1973) & 1 \\
\hline Bertolanius smreczynskii (Weglarska, 1980)* & 1 & Isohypsibius brevispinosus (Iharos, 1966) & 1 \\
\hline Calohypsibius schusteri Nelson and McGlothlin, 1996 & 1 & Isohypsibius kenodontis Kendall-Fite and Nelson, 1996 & 3 \\
\hline Diphascon belgicae Richters, $1911^{*}$ & 6 & Isohypsibius lunulatus (Iharos, 1966) & 5 \\
\hline Diphascon bullatum Murray, $190 * 5$ & 3 & Isohypsibius sattleri (Richters, 1902)* & 5 \\
\hline Diphascon carolae Binda and Pilato, 1969 & 6 & Isohypsibius tuberculatus group* & 3 \\
\hline Diphascon higginsi Binda, 1971 & 10 & Itaquascon pawlowski Węglarska, 1973* & 1 \\
\hline Diphascon nobile (Binda, 1969)* & 6 & Macrobiotus harmsworthi Murray, $1907^{*}$ & 63 \\
\hline Diphascon nodulosum (Ramazzotti, 1957) & 3 & Macrobiotus hufelandi C.A.S. Schultze, $1833^{*}$ & 5 \\
\hline Diphascon patanei Binda and Pilato, $1971^{*}$ & 3 & Macrobiotus martini Bartels et al., 2009 & 5 \\
\hline Diphascon pinguiforme Pilato and Binda, 1997/98* & 17 & Macrobiotus nelsonae Guidetti, 1998* & 26 \\
\hline Diphascon scoticum Murray, $1905^{*}$ & 14 & Macrobiotus pallarii Maucci, 1954 & 22 \\
\hline Doryphoribius smokiensis Bartles et al., 2007* & 2 & Mesocrista spitzbergensis (Richters, 1903)* & 2 \\
\hline Echiniscus horningi Schuster and Grigarick, 1971 & 3 & Milnesium spp. & 3 \\
\hline Echiniscus maucci Ramazzotti, 1956 & 3 & Minibiotus intermedius (Plate, 1888) & 10 \\
\hline Echiniscus virginicus Riggin, 1962 & 5 & Paramacrobiotus halei (Bartels et al., 2009)* & 21 \\
\hline Hypechiniscus gladiator (Murray, 1905) & 3 & Paramacrobiotus tonollii (Ramazzotti, 1956) & 11 \\
\hline Hypsibius cf. dujardini & 3 & Platicrista angustata (Murray, 1905)* & 5 \\
\hline Hypsibius convergens (Urbanowicz, 1925)* & 16 & Pseudechiniscus brevimontanus Kendall-Fite and Nelson, 1996 & 2 \\
\hline Hypsibius dujardini (Doyère, 1840) & 1 & Pseudechiniscus suillus group & 5 \\
\hline \multirow[t]{2}{*}{ Hypsibius roanensis Nelson and McGlothlin, 1993} & 3 & Ramazzottius baumanni (Ramazzotti, 1962) & 2 \\
\hline & & Ramazzottius oberhaeuseri group & 2 \\
\hline
\end{tabular}

*Species that predominantly or only occurred in soil/leaf litter habitats versus moss, lichen, or aquatic habitats. Numbers are those of samples $(=$ occurrences) out of 114 total samples containing tardigrades.

Tab. 2. Tardigrade species richness in previous soil/leaf litter studies. See the Discussion for details on substrate and vegetation types.

\begin{tabular}{ccll}
\hline \# Species & \# Samples & Location & References \\
\hline 10 & 300 & Denmark & Hallas and Yeates, 1972 \\
6 & 32 & Ohio, USA & Fleeger and Hummon, 1975 \\
32 & 60 & Roan mt., TN, USA & Guidetti et al., 1999 \\
20 & 15 & Italy & Guidetti et al., 1999 \\
40 & 150 & Mt. Fuji, Japan & Ito, 1999 \\
34 & 94 & Costa Rica & Kaczmarek 2003, pers. com. \\
47 & 90 & Kanagawa, Japan & Harada and Ito, 2006 \\
14 & 45 & Germany & Hohberg, 2006 \\
39 & 144 & Spain & Guil, personal communication \\
10 & 44 & Louisiana, FL, USA & Hinton et al., 2010 \\
\hline
\end{tabular}


(2008) collected tardigrades, nematodes, and rotifers on nunataks (mountain peaks above the ice sheet) in Antarctica. Tardigrades were common in moss and in fellfield soils (treeless, windy, stony areas) but not in ornithogenic soils (those created by penguin rookeries). The high variability in microfauna densities in similar habitats made it difficult to find significant differences among populations, however the abundances of tardigrades and rotifers were positively correlated.

\section{Anthroprogenic effects}

Fleeger and Hummon (1975) investigated the effects of cultivation on depth distribution and abundance of six species of tardigrades over four months in an old field pasture in Ohio, USA. They found a seasonal effect related to soil moisture and noted a cultivation effect after a late summer drought that changed soil structure.

Leetham et al. (1982) studied the effect of experimentally elevated, chronic low levels of $\mathrm{SO}_{2}$ on soil tardigrades in a northern mixed-grass prairie in Montana, USA. Three genera were recognized in the upper $2 \mathrm{~cm}$ of soil, but not identified to species. Although the variability in total counts of tardigrades between samples was high, there appeared to be a substantial reduction of tardigrades with increased concentrations of $\mathrm{SO}_{2}$.

The impacts of clear-cutting and forest management practices on litter, humus and soil microfauna (nematodes, rotifers, and tardigrades) in a Swedish pine forest (Pinus sylvestris, L.) were investigated by Sohlenius (1982). Tardigrade abundance was highest in the litter layer in clearcut areas with slash (branches left as cutting waste) compared to those in which slash was removed during the three-year period, but high variation in total number of organisms between samples hindered further analysis. Similarly, Uhía and Briones (2002) collected monthly samples of tardigrades and enchytraeids for a year in a deforested pine forest (Pinus pinaster Aiton) in Spain. Tardigrades were not identified to species and only total numbers were recorded. There was a significantly higher number of tardigrades in deforested sites than forested sites except for two months, with concentrations of tardigrades in the upper $2 \mathrm{~cm}$ of soil.

Hohberg (2006) found 14 species of soil eutardigrades in a German deforested mine reclamation site, characterized by high within-site variance in tardigrade numbers. Tardigrade abundance was higher in younger soils, with the youngest site dominated by Hypsibius pallidus Thulin, 1911. Overall, however, the carnivorous Paramacrobiotus richtersi (Murray, 1911) was the dominant species. She did not find significant correlations between tardigrade species distributions and abundance with various environmental factors. In another post-mining site in Germany, Hohberg et al. (2011) studied undisturbed primary succession of the soil tardigrade community over a four-year period, with the algal-feeder Apodibius confusus Dastych, 1983 being the initial coloniser and overall dominant species. The spatial frequency of $A$. confusus increased dramatically over time, as did tardigrade diversity. These hotspots of $A$. confusus were not correlated with soil mositure or vegetation, but were likely sites where anhydrobiotic $A$. confusus arrived at the site, transported by wind.

\section{Statistical studies}

Harada and Ito (2006) reported a multivariate statistical analysis of 47 species of Japanese soil tardigrades from nine forests in four vegetation types (broadleaf

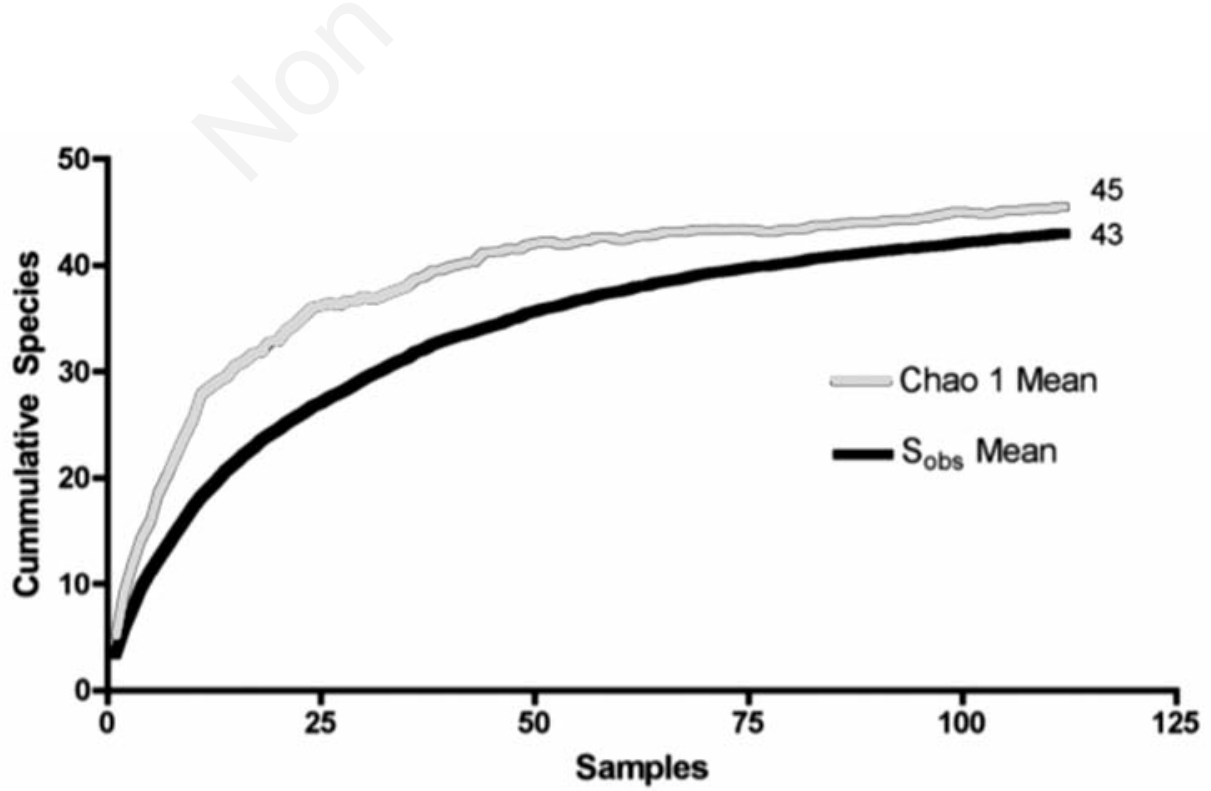

Fig. 2. Species accumulation curve and Chao1 species richness estimate for all soil/leaf litter samples. 
(evergreen/decidious), coniferous, and orchard. They analysed 23 environmental variables and found nematode frequency and soil porosity to be the only variables showing a significant impact on tardigrade species composition across their study sites. In addition, Guil (2008) and Guil et al. (2009) used parametric and non-parametric statistics to determine relationships between environmental variables and tardigrade species diversity and abundance in a large-scale, multihabitat study that included leaf-litter. Leaf litter had the highest species richness but low abundance of eutardigrades (39 species, Guil, personal communication). Average tardigrade density ranged from 0 to $1,222,222$ specimens $\mathrm{m}^{-2}$ in the habitats analysed.

\section{Great Smoky Mountains National Park study}

The species list for all $150 \mathrm{GSMNP}$ soil/leaf litter samples includes 43 species, and based on the Chao1 species richness estimate (Fig. 2), this is a nearly complete census of species from this substrate in the park. Nineteen are truly edaphic species (Tab. 1). Two of these nineteen are recently described species (Doryphoribius smokiensis Bartels, Nelson, Kaczmarek, and Michalczyk, 2007; Paramacrobiotus halei Bartels, Nelson, Pilato, and Lisi, 2009). The accidental species also include a recently described species, Macrobiotus martini Bartels, Nelson, Pi-

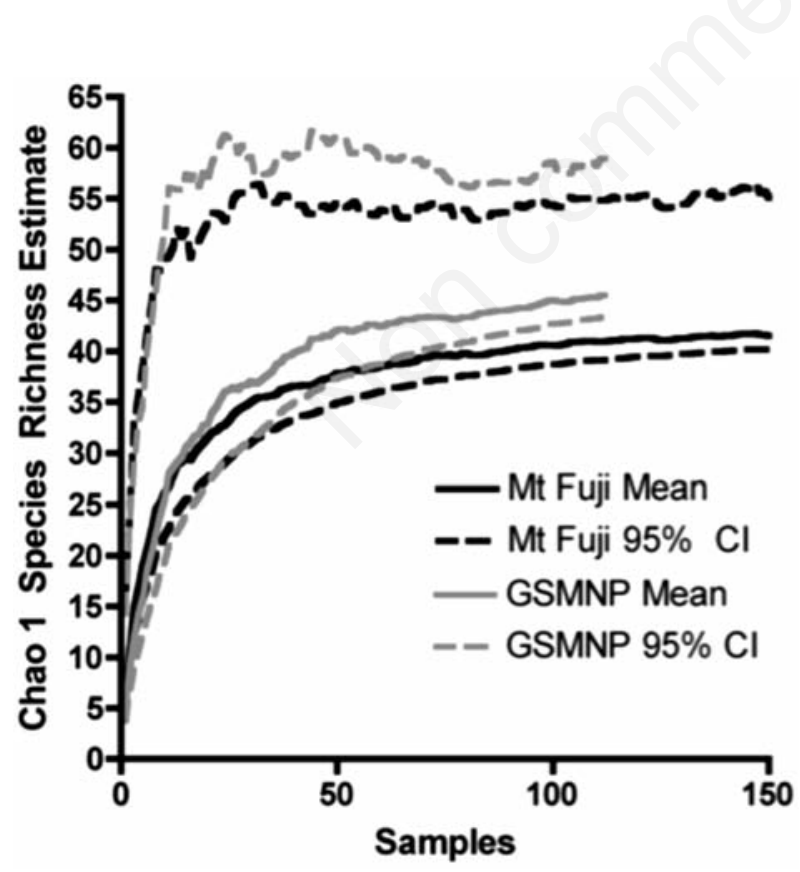

Fig. 3. Chao 1 species richness estimates for the Great Smoky Mountains National Park and mt. Fuji, Japan (Ito, 1999). Means and $95 \%$ confidence intervals (CIs) are indicated. Note that upper $\mathrm{CI}$ is much higher than the mean. The lower CI is smaller than upper CI because it is constrained by the actual number of species observed. lato, and Lisi, 2009, and an undescribed new species of Milnesium. In addition to these new species, two of the species in our soil samples appear to be endemic to the Southern Appalachian mountains: Hypsibius roanensis Nelson and McGlothlin, 1993 and Macrobiotus nelsonae Guidetti, 1998, both described from Roan mountain, Tennessee (USA).

Comparing species richness between geographic areas (Tab. 2) is complicated by variation in scale of the region surveyed, sampling techniques, and sampling effort. Even between and within adjacent substrates that appeared similar, high spatial variability was found in tardigrade populations in cryptogams (Meyer, 2006), confirming the characteristic patchiness of tardigrade distributions. Therefore numerous replicate samples must be taken to obtain valid data to determine significant patterns of tardigrade distribution and diversity. Preliminary sampling for variance, before testing ecological hypotheses, was strongly supported but the additional time investment for quantitative research was acknowledged (Meyer, 2006). Degma et al. (2011) hypothesised random recruitment and slow dissemination of subsequent micro-populations to explain tardigrade heterogenenity (aggregated distributions) in randomly collected substrate samples. They suggested increasing the number and/or size of samples, or sampling different parts of the substrate, to reduce variation in tardigrade abundance and diversity.

The comparison of Chaol species richness estimates (Fig. 3) indicated a slightly higher diversity in GSMNP than mt. Fuji, Japan, and the t-test showed this difference was significant. This is remarkable given that the mt. Fuji samples consisted of four times the volume of our sample. Soil species richness was higher than GSMNP only in the Harada and Ito (2006) study in the Kanagawa prefecture of Japan, but raw data from the Kanagawa study was not available for statistical analysis.

\section{CONCLUSIONS}

We found high species richness (43 species) of soil/leaf litter tardigrades in the areas that we sampled in the Great Smoky Mountains National Park, North Carolina/Tennessee. The Chao 1 species richness estimate and species accumulation curve for the GSMNP confirmed that our species list is virtually complete and significantly higher than species richness in soil data from mt. Fuji, Japan. Only one study (Harada and Ito, 2006) reported a higher number of species (47) than the GSMNP. Species richness estimators are valuable tools for comparing diversity in different habitats, even when sampling effort varies between studies.

\section{ACKNOWLEDGMENTS}

We sincerely thank the students at Warren Wilson Col- 
lege for processing samples and making slides. Drs. Kaczmarek, Michalczyk, Pilato, Lisi, Guidetti and Bertolani and others greatly assisted in confirmation of some species identifications. Dr. Masamichi T. Ito graciously shared his mt. Fuji data for our comparative analysis, and Dr. Noemi Guil sent summary statistics from her Iberian leaf litter study. We appreciate the diligent work of the organisers of the $12^{\text {th }}$ International Symposium in Porto, especially our friend and colleague Paulo, and well as the constructive comments of the editors and reviewers. This work would not have been possible without the long-term funding from Discover Life in America. We are grateful to our respective universities (East Tennessee State University and Warren Wilson College) for the use of our laboratories and for partial travel support to attend the symposium.

\section{REFERENCES}

Bartels PJ, Nelson DR, 2006. A large-scale, multihabitat inventory of the phylum Tardigrada in the Great Smoky Mountains National Park, USA: a preliminary report. Hydrobiologia 558:111-118.

Bartels PJ, Nelson DR, 2007. An evaluation of species richness estimators for tardigrades of the Great Smoky Mountains National Park, TN and NC, USA. J. Limnol. 66(Suppl. 1):104110.

Bartels PJ, Nelson DR, 2012. An online key and field guide to the tardigrades of the Great Smoky Mountains National Park (North Carolina \& Tennessee, USA, North America) with taxonomic revisions of two species. Zootaxa 3249:67-68.

Bartels PJ, Nelson DR, Exline RP, 2011b. Allometry and correcting for body size in the biometric analysis of tardigrades. J. Syst. Zool. Evol. Res. 49(Suppl. 1):17-25.

Bartels PJ, Nelson DR, Kaczmarek Ł, Michalczyk Ł, 2007. Doryphoribius smokiensis, a new species of Eutardigrada (Hypsibiidae) from the Great Smoky Mountains National Park TN, USA (North America). Zootaxa 1646:59-65.

Bartels PJ, Nelson DR, Kaczmarek Ł, Michalczyk Ł, 2008. Three new species and one new record of the genus Doryphoribius Pilato, 1969 (Tardigrada: Eutardigrada: Hypsibiidae) from the Great Smoky Mountains National Park (Tennessee, USA). J. Nat. Hist. 42:2595-2608.

Bartels PJ, Nelson DR, Kaczmarek Ł, Michalczyk Ł, 2011a. Ramazzottius belubellus, a new species of Tardigrada (Eutardigrada: Parachela: Hypsibiidae) from the Great Smoky Mountains National Park (North Carolina, USA). Proc. Biol. Soc. Wash. 124:23-27.

Bartels PJ, Pilato G, Lisi O, Nelson DR, 2009. Macrobiotus (Eutardigrada, Macrobiotidae) from the Great Smoky Mountains National Park, Tennessee/North Carolina, USA (North America): two new species and six new records. Zootaxa 2022:45-57.

Colwell RK, 2009. EstimateS: statistical estimation of species richness and shared species from samples. Version 8.2. User's guide and application. Available from: http://viceroy. eeb.uconn.edu/estimates

Degma P, Katina S, Sabatovičová L, 2011. Horizontal distribution of moisture and Tardigrada in a single moss cushion. J. Zool. Syst. Evol. Res. 49(Suppl. 1):71-77.
Elith J, Phillips SJ, Hastie T, Dudı'k M, Chee YE, Yates CJ, 2011. A statistical explanation of MaxEnt for ecologists. Divers. Distrib. 17:43-57.

Fleeger J, Hummon W, 1975. Distribution and abundance of soil Tardigrada in cultivated and uncultivated plots of an old field pasture. Mem. Ist. Ital. Idrobiol. (Suppl. 32):93-112.

Guidetti R, Bertolani R, Nelson DR, 1999. Ecological and faunistic studies on tardigrades in leaf litter of beech forests. Zool. Anz. 238:215-223.

Guil N, 2008. New records and within-species variability of Iberian tardigrades (Tardigrada) with comments on the species from the Echinscus blumi-canadensis series. Zootaxa 1757:1-30.

Guil N, Hortal J, Sánchez-Moreno S, Machordom A, 2009. Effects of macro and micro-environmental factors on the species richness of terrestrial tardigrade assemblages in an Iberian mountain environment. Landscape Ecol. 24:375390.

Hallas T, Yeates G, 1972. Tardigrada of the soil and litter of a Danish beech forest. Pedobiologia 12:287-304.

Harada H, Ito MT, 2006. Soil-inhabiting tardigrade communities in forests of central Japan. Hydrobiologia 558:119-127.

Hinton J, Meyer H, Sweeney A, 2010. Seasonal and spatial variation in diversity and abundance of tardigrades in leaf litter from Louisiana and Florida. Southwest. Nat. 55:539-543.

Hohberg K, 2006. Tardigrade species composition in young soils and some aspects on life history of Macrobiotus richtersi $\mathrm{J}$. Murray, 1911. Pedobiologia 50:267-274.

Hohberg K, Russell DJ, Elmer M, 2011. Mass occurrence of algal-feeding tardigrade Apodibius confusus, in the young soils of a post-mining site. J. Zool. Syst. Evol. Res. 49(Suppl. 1):62-65.

Ito MT, 1999. Ecological distribution, abundance and habitat preference of terrestrial tardigrades in various forests on the northern slope of Mt. Fuji, Central Japan. Zool. Anz. 238:225-234.

Ito MT, Abe W, 2001. Micro-distribution of soil inhabiting tardigrades (Tardigrada) in a sub-alpine coniferous forest of Japan. Zool. Anz. 240:403-407.

Jenkins MA, 2007. Vegetation communities of Great Smoky Mountains National Park. Southeastern Nat. 6(Special Issue 1):35-56.

Kaczmarek L, 2003. New records of and key to Tardigrada from Costa Rica. Zootaxa 177:1-4.

Leetham JW, McNary TJ, Dodd JL, Laurenroth WK, 1980. Response of soil nematodes, rotifers, and tardigrades to three levels of season long sulfur dioxide exposures. Water Air Soil Pollut. 17:343-356.

Leetham JW, McNary TJ, Dodd JL, Laurenroth WK, 1982. Response of field populations of Tardigrada to various levels of chronic low-level sulphur dioxide exposure, p. 382-390. In: D.L. Dindal (ed.), Soil biology as related to land use practices. Proceedings of the VII International Soil Zoology Colloquium of the International Society of Soil Science. U.S. Environmental Protection Agency ed.

Manicardi GC, Bertolani R, 1987. First contribution to the knowledge of alpine grassland tardigrades. p. 177-185. In: R. Bertolani (ed.), Biology of Tardigrades. Selected Symposia and Monographs. U.Z.I. Mucchi ed.

Meyer H, 2006. Small-scale spatial distribution variability in 
terrestrial tardigrade populations. Hydrobiologia 558:133139.

Moorhead DL, Barrett JE, Virginia RA, Wall DH, Porazinska D, 2003. Organic matter and soil biota of upland wetlands in Taylor Valley, Antarctica. Polar Biol. 26:567-576.

Nelson DR, Bartels PJ, 2007. "Smoky Bears": Tardigrades of the Great Smoky Mountains National Park. Southeastern Nat. 6(Special Issue 1):229-238.

Petz W, 1997. Ecology of the active soil microfauna (Protozoa, Metazoa) of Wilkes Land, East Antarctica. Polar Biol. 18:33-44.

Porazinska D, Wall DH, Virginia RA, 2002. Invertebrates in ornithogenic soils on Ross Island, Antarctica. Polar Biol. 25:569-574.

Sohlenius B, 1982. Short-term influence of clear-cutting on abundance of soil-microfauna (Nematoda, Rotatoria and Tardigrada) in a Swedish pine forest soil. J. Appl. Ecol. 19:349-359.

Sohlenius B, Boström S, 2008. Species diversity and random distribution of microfauna in extremely isolated habitable patches on Antarctic nunataks. Polar Biol. 31:817-825.

Sohlenius B, Boström S, Jönsson KI, 2004. Occurrence of ne- matodes, rotifers and tardigrades on ice-free areas in East Antarctica. Pedobiologia 48:395-408.

Uhía E, Briones MJI, 2002. Population dynamics and vertical distribution of enchytraeids and tardigrades in response to deforestation. Acta Oecol. 23:349-359.

Wall DH, Behan-Pelletier V, Covich AP, Snelgrove P, 2007. Hidden assets: Biodiversity below-surface. UNESCO-SCOPE ed., Paris, France.

Wall DH, Fitter AH, Paul EA, 2005. Developing new perspectives from advances in soil biodiversity research, p. 3-27. In: R.D. Bardgett, D.W. Hopkins and M.B. Usher (eds.), Biological diversity and function in soils. Cambridge University Press.

White RD, Patterson KD, Weakley A, Ulrey CJ, Drake J. 2003. Vegetation classification of Great Smoky Mountains National Park. Report submitted to BRD-NPS Vegetation Mapping Program. Nature Serve, Durham, USA: 376 pp.

Wu T, Ayres E, Li G, Bardgett RD, Wall DH, Garey JR, 2009. Molecular profiling of soil animal diversity in natural ecosystems: incongruence of molecular and morphological results. Soil Biol. Biochem. 41:849-857. 